\title{
Optimal Adaptive Control and Backstepping Control Method with Sliding Mode Differentiator
}

\author{
Shengxin Sun $(\mathbb{D}$, Yang Zhao $\mathbb{1}$, and Hao Wu $(\mathbb{C})$ \\ School of Astronautics, Harbin Institute of Technology, Harbin, China \\ Correspondence should be addressed to Shengxin Sun; 16b918086@stu.hit.edu.cn
}

Received 29 March 2021; Revised 12 June 2021; Accepted 6 July 2021; Published 15 July 2021

Academic Editor: Weixiang Zhou

Copyright ( 2021 Shengxin Sun et al. This is an open access article distributed under the Creative Commons Attribution License, which permits unrestricted use, distribution, and reproduction in any medium, provided the original work is properly cited.

\begin{abstract}
In order to improve the success rate of space debris object capture, how to increase the resistance to interference in the space robot arm has become an issue of interest. In addition, since the space operation time is always limited, finite-time control has become another urgent requirement needed to be addressed. Considering external disturbances, two control methods are proposed in this paper to solve the control problem of space robot arm. Firstly, a linear sliding mode control method is proposed considering the model uncertainties and external disturbances. The robot arm can track the desired trajectory, while a trade-off between optimality and robustness of the solved system can be achieved. Then, in order to reduce conservativeness and relax restrictions on external disturbances, a novel backstepping control method based on a finite-time integral sliding mode disturbance observer is developed, which compensates for the effects of both model uncertainties and infinite energy-based disturbance inputs. Finally, simulation examples are given to illustrate the effectiveness of the proposed control method.
\end{abstract}

\section{Introduction}

With the rapid growth of space projects in the last several decades, the increasing space debris residues from satellites scrapped in space bring huge threat to the existing on-orbit spacecraft [1]. Therefore, how to reduce the amount of space debris and effectively lower their risk level becomes more and more urgent. Under this background, Active Debris Removal (ADR) has become a worldwide research hotspot [2-4].

Space debris is mostly discarded space scrap, which is out of control and eventually moves freely due to complex nutation. Since these high-speed tumbling targets are very difficult to catch directly, it is necessary to reduce the relative speed between the chaser and the target before the next onorbit capture [5-8]. Thus, the final capture of the target can be achieved when the relative speed is slow enough $[9,10]$.

In terms of control for system with uncertainties and disturbances, numerous methods are proposed. Focused on solving the problem of asynchronous phenomena with different solutions, Cheng et al. [11-13] proposed a finite-time backstepping control method by incorporating a hidden Markov model, and the finite-time asynchronous control is achieved in the end. Considering time-varying full-state constraints and uncertainties, an adaptive fuzzy backstepping control was proposed for nonlinear state-constrained systems by Zhou et al. [14-16], and the parameter updating law is different compared with existing adaptive updating methods. By using the integral sliding mode design method for nonlinear stochastic systems, Wang et al. [17, 18] presented a new integral sliding mode control for fuzzy stochastic systems subjected to matched/mismatched uncertainties. The asymptotic stability of sliding mode dynamics is guaranteed while a simple search algorithm is provided to find the stability bound. Liu et al. $[19,20]$ proposed universal adaptive control to solve the universal control problem of a class of uncertain nonlinear systems. Yang and Tan [21, 22] designed an adaptive neural network for sliding mode control of flexible manipulators. However, the conservativeness and strict restrictions of the disturbances of the above controller are still needed to be addressed.

Taking into account the phenomenon of disturbing moments in real systems, robust control with disturbance observer is an efficient control scheme to address it. The essence of robust control is to maintain the robustness of a 
closed-loop system. Robustness refers to the ability of a control system to maintain certain properties of the system under certain parameter regimes. Robust control theory is the theory of robustness in space by optimising certain performance indicators with infinite parameters. So, in this paper, a robust control system for a robotic arm will be designed based on the backstepping method and the model will be compensated with a finite-time integral sliding mode disturbance observer in that it can approximate the disturbance moment vector well. Thus, the system can achieve accurate tracking of the robotic arm attitude command.

Considering all the above practical challenges, in this paper, we study the stabilization problem of the flexible deceleration brush detumbling mechanism attached to a space robot arm. Two sliding mode control methods are developed to solve this problem. First, an optimal $\mathrm{H}_{\infty}$ sliding mode control law is proposed for space multijoint robotic manipulator with consideration of both optimality and robustness of the detumbling system. The proposed control law can stabilize the overall closed-loop system with a prescribed $H_{\infty}$ performance level. Moreover, in this design, by using the weighting matrix method, the balance between the optimality and robustness of the detumbling system is achieved. Second, considering the fact that in practical space, the external disturbance always refers to the mismatched type, a novel backstepping control law with the finite-time integral sliding mode disturbance observer is developed, which can compensate the effects of model uncertainty and mismatched disturbance input simultaneously. Finally, simulation examples are given to verify the accuracy and effectiveness of the controller.

\section{Materials and Methods}

2.1. Design of Robust Sliding Mode Controller. With the consideration of microgravity environment, the potential energy of the system can be ignored. Then, the Lagrange function of the total kinetic energy of the space robot system can be expressed as

$$
L=\frac{1}{2} \dot{q}_{t o g}^{T} H \dot{q}_{t o g}
$$

where

$$
\begin{aligned}
& \dot{q}_{\text {tog }}=\left[{ }^{I}{{ }}_{0}{ }^{I} \omega_{0} \dot{q}\right]^{T}, \\
& H=\left[\begin{array}{ccc}
M E_{3} & -M r_{0 g}^{\times} & \sum_{i=1}^{7} m_{i} J_{T i} \\
M r_{0 g}^{\times} & \sum_{i=0}^{7}\left(I_{i}-m_{i} r_{0 i}^{\times} r_{0 i}^{\times}\right) & \sum_{i=1}^{7}\left(I_{i} J_{R i}+m_{i} r_{0 i}^{\times} J_{T i}\right) \\
\sum_{i=1}^{7}\left(m_{i} J_{T i}^{T}\right) & \sum_{i=1}^{7}\left(\left(J_{R i}\right)^{T} I_{i}-m_{i}\left(J_{T i}\right)^{T} r_{0 i}^{\times}\right) & \sum_{i=1}^{7}\left(\left(J_{R i}\right)^{T} I_{i} J_{R i}+m_{i}\left(J_{T i}\right)^{T} J_{T i}\right)
\end{array}\right], \\
& J_{R i}=\left[\begin{array}{llllll}
k_{1} & \cdots & k_{i} & 0 & \cdots & 0
\end{array}\right] \in R^{3 \times 7}, \\
& J_{T i}=\left[\begin{array}{llllll}
k_{1} \times\left(r_{i}-p_{1}\right) & \cdots & k_{i} \times\left(r_{i}-p_{i}\right) & 0 & \cdots & 0
\end{array}\right] \in R^{3 \times 7},
\end{aligned}
$$

where $\mathrm{r}_{0 g}^{\times}$is $\mathrm{r}_{0 g} \times,{ }^{I} v_{0}$ is the linear velocity of the base, ${ }^{I} \omega_{0}$ is the angular velocity of the base, $m_{i}$ is the mass of the $i$ th rod of the space robot, $\mathbf{q}=\left[q_{1}, q_{2}, q_{3}, q_{4}, q_{5}, q_{6}, q_{7}\right] \in \mathbf{R}^{7}$ are the variables of each joint of the manipulator, $\mathbf{J}_{i}$ is the joint that connects the $i-1$ th link and the $i$ th link, ${ }^{I} \mathbf{r}_{i} \in \mathbf{R}^{3}$ is the position vector of the centre of mass of the $i$ th lever of the manipulator in an inertial coordinate system, ${ }^{I} p_{i} \in R^{3}$ is the position vector of the $i$ th joint in an inertial frame, $m_{i}$ is the mass of the $i$ th bar of the space robot, $I_{i}$ is the inertial of $i$ th link, and $M$ is a given constant.

By using the Lagrange equation

$$
\frac{\mathrm{d}}{\mathrm{d} t}\left(\frac{\partial L}{\partial \dot{q}_{\text {tog }}}\right)-\frac{\partial L}{\partial q_{t o g}}=\tau,
$$

the dynamic equation of the space robot system can be obtained as follows:

$$
H\left(q_{t o g}\right) \ddot{q}_{t o g}+C\left(q_{t o g}, \dot{q}_{t o g}\right) \dot{q}_{t o g}=\tau,
$$

where $H\left(q_{t o g}\right)$ is the symmetric positive definite inertial matrix, $C\left(q_{\text {tog }}, \dot{q}_{\text {tog }}\right)$ is a nonlinear term satisfying
$C\left(q_{t o g}, \dot{q}_{t o g}\right) \dot{q}_{t o g}=\dot{H}\left(q_{t o g}\right) \dot{q}_{t o g}-\left(\partial / \partial q_{t o g}\right)\left((1 / 2) \dot{q}_{t o g}^{T} H \dot{q}_{t o g}\right)$, and $\tau$ is the external control force and torque.

Since the space racemization robot works in a complex microgravity environment, considering uncertainties such as external disturbance, friction, and parameter error, equation (4) can be further expressed as follows:

$$
\begin{aligned}
& H\left(q_{t o g}\right) \ddot{q}_{t o g}+C\left(q_{t o g}, \dot{q}_{t o g}\right) \dot{q}_{t o g}=\tau, \\
& H\left(q_{t o g}\right)=H_{0}\left(q_{t o g}\right)+\Delta H\left(q_{t o g}\right), \\
& C\left(q_{t o g}, \dot{q}_{t o g}\right)=C_{0}\left(q_{t o g}, \dot{q}_{t o g}\right)+\Delta C\left(q_{t o g}, \dot{q}_{t o g}\right),
\end{aligned}
$$

where $H_{0}\left(q_{\text {tog }}\right)$ and $C_{0}\left(q_{\text {tog }}, \dot{q}_{\text {tog }}\right)$ are nominal matrices and $\Delta H\left(q_{\text {tog }}\right)$ and $\Delta C\left(q_{\text {tog }}, \dot{q}_{\text {tog }}\right)$ are the corresponding uncertain matrices. Then, the above equation can be further rewritten as

$$
\begin{aligned}
& H_{0}\left(q_{t o g}\right) \ddot{q}_{t o g}+C_{0}\left(q_{t o g}, \dot{q}_{t o g}\right) \dot{q}_{t o g} \\
& \quad=\tau-\Delta H\left(q_{t o g}\right) \ddot{q}_{t o g}-\Delta C\left(q_{t o g}, \dot{q}_{t o g}\right) \dot{q}_{t o g} .
\end{aligned}
$$

Define the dynamic compensation as 


$$
\begin{aligned}
\tau & =H_{0}\left(q_{t o g}\right) u+C_{0}\left(q_{t o g}, \dot{q}_{t o g}\right) \dot{q}_{t o g}, \\
\ddot{q}_{t o g} & =u-H_{0}^{-1} \Delta H \ddot{q}_{t o g}-H_{0}^{-1} \Delta C \dot{q}_{t o g},
\end{aligned}
$$

where $u$ is control input vector, and then define the external disturbances $\tau_{d}$ as

$$
\delta\left(q_{\text {tog }}, \dot{q}_{\text {tog }}, \ddot{q}_{\text {tog }}\right)=-\left(\Delta H \ddot{q}_{\text {tog }}+\Delta C \dot{q}_{\text {tog }}-\tau_{d}\right) .
$$

In order to make the space robot end track the timevarying desired trajectory, the state tracking error $e \in R^{13}$ is defined as

$$
e=\left[\begin{array}{l}
\dot{q}_{t o g}-\dot{q}_{t o g}^{d} \\
q_{t o g}-q_{t o g}^{d}
\end{array}\right]=\left[\begin{array}{l}
\dot{\tilde{q}}_{t o g} \\
\tilde{q}_{t o g}
\end{array}\right],
$$

where $q_{\text {tog }}^{d}$ is the desired joint angle and $\dot{q}_{\text {tog }}^{d}$ is the desired joint angular velocity.

The trajectory tracking error equation of the space robot can then be obtained as follows:

$$
\dot{e}=A\left(q_{t o g}, \dot{q}_{t o g}\right) e+B u+B w,
$$

where each parameter is specifically defined as

$$
\begin{aligned}
A\left(q_{\text {tog }}, \dot{q}_{\text {tog }}\right) & =\left[\begin{array}{cc}
-H_{0}^{-1} C_{0} & 0 \\
I_{13} & 0
\end{array}\right], \\
B & =\left[\begin{array}{ll}
I_{13} & 0
\end{array}\right]^{T}, \\
w & =-H_{0}^{-1} \delta\left(q_{\text {tog }}, \dot{q}_{\text {tog }}, \ddot{q}_{\text {tog }}\right), \\
u & =H_{0}^{-1}\left(\tau-H_{0} \ddot{q}_{\text {tog }}^{d}-C_{0} \dot{q}_{\text {tog }}^{d}\right) .
\end{aligned}
$$

$$
\begin{aligned}
& \tau=H_{0} \ddot{q}_{t o g}+C_{0} \dot{q}_{\text {tog }}^{d}, \\
& \ddot{q}_{\text {tog }}=\ddot{q}_{\text {tog }}^{d}+\left(-D_{11}^{-1} H_{0}^{-1} C_{0} D_{11}-D_{11}^{-1} D_{12}\right) \dot{e}-D_{11}^{-1} H_{0}^{-1} C_{0} D_{12} e+D_{11}^{-1} H_{0}^{-1} u
\end{aligned}
$$

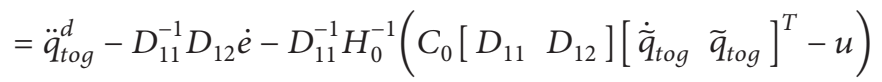

$$
\begin{aligned}
& =\ddot{q}_{\text {tog }}^{d}-D_{11}^{-1} D_{12} \dot{\tilde{q}}_{t o g}-D_{11}^{-1} H_{0}^{-1}\left(C_{0} D_{1} \dot{e}-u\right) \text {. }
\end{aligned}
$$

Therefore, the force and torque exerted on the space robot can be solved as

$$
\tau=H_{0}\left(\ddot{q}_{\text {tog }}^{d}+u\right)+C_{0} \dot{q}_{\text {tog }}^{d} .
$$

In order to facilitate the tracking control of the desired trajectory and reach the desired racemate point at the end, an auxiliary equation is designed as

$$
z=D e=\left[\begin{array}{cc}
D_{11} & D_{12} \\
0 & I
\end{array}\right]\left[\begin{array}{l}
\dot{\tilde{q}}_{t o g} \\
\tilde{q}_{t o g}
\end{array}\right],
$$

where $D_{11}$ and $D_{12}$ are constant matrices.

Substituting equation (13) into equation (10) yields

$$
\dot{e}=A_{N} e+B_{N} u+B_{N} w,
$$

where

$$
\begin{aligned}
A_{N} & =D^{-1}\left[\begin{array}{cc}
-H_{0}^{-1} C_{0} & 0 \\
D_{11}^{-1} & -D_{11}^{-1} D_{12}
\end{array}\right] D, \\
B_{N} & =D^{-1}\left[\begin{array}{c}
H_{0}^{-1} \\
0
\end{array}\right], \\
D_{1} & =\left[\begin{array}{cc}
D_{11} & D_{12}
\end{array}\right], \\
u & =H_{0} D_{1} \dot{e}+C_{0} D_{1} e, \\
w & =H_{0} D_{11} H_{0}^{-1} \delta\left(q_{\text {tog }}, \dot{q}_{\text {tog }}, \ddot{q}_{\text {tog }}\right) .
\end{aligned}
$$

Then, the control force and torque of the space robot can be expressed as
By designing $u=-K e(t)$, the external disturbance $w$ in the system can be reduced. Given any positive real number $\gamma$, we have

$$
J=\min _{u \in L_{2}} \max _{0 \neq w \in L_{2}} \frac{\int_{0}^{\infty}\left((1 / 2) e^{T} Q e+(1 / 2) u^{T} R u\right) \mathrm{d} t}{\int_{0}^{\infty}\left((1 / 2) w^{T} w\right) \mathrm{d} t} \leq \gamma^{2} .
$$

Design the Lyapunov function $V(x)=(1 / 2) x^{T} P x$, and then the Riccati equation can be solved as follows:

$$
\dot{P}+P A_{N}+A_{N} P+P B_{N}\left(R^{-1}-\frac{1}{\gamma^{2}} I\right) B_{N} P+Q=0 .
$$

With $C_{0}-(1 / 2) M_{0}$ being skew symmetric, $P$ can be designed as

$$
P=D^{T}\left[\begin{array}{cc}
M_{0} & 0 \\
0 & N
\end{array}\right] D
$$

where $N$ is a positive definite symmetric constant matrix. obtain

$$
\left[\begin{array}{ll}
0 & N \\
N & 0
\end{array}\right]-D^{T} B_{N}\left(R^{-1}-\frac{1}{\gamma^{2}} I\right) B_{N}^{T} D+Q=0 .
$$

By utilizing Cholesky decomposition method, we can have

$$
R_{1}^{T} R_{1}=\left(R^{-1}-\frac{1}{\gamma^{2}} I\right)^{-1} .
$$

At the same time:

$$
\begin{aligned}
& Q=\left[\begin{array}{cc}
Q_{1}^{T} Q_{1} & Q_{12} \\
Q_{12}^{T} & Q_{2}^{T} Q_{2}
\end{array}\right], \\
& D=\left[\begin{array}{cc}
R_{1}^{T} Q_{1} & R_{1}^{T} Q_{2} \\
0 & I
\end{array}\right],
\end{aligned}
$$




$$
N=\frac{1}{2}\left(Q_{1}^{T} Q_{2}+Q_{2}^{T} Q_{1}\right)-\frac{1}{2}\left(Q_{21}^{T}+Q_{12}\right)
$$

Therefore, the robust optimal $\mathbf{H}_{\infty}$ state feedback controller can be designed as

$$
u=-R^{-1} B^{T} D e .
$$

\subsection{Design of Backstepping Controller with Finite-Time} Observer. In the previous section, we design an $H_{\infty}$ sliding mode control law for space multijoint robotic manipulator, which can stabilize the overall closed-loop system with a prescribed $H_{\infty}$ performance level. It should be pointed out that in the previous control approach, the model uncertainty $\Delta A(x)$ is dealt with the robust control framework via the LMI technique, which may bring conservativeness in practical application when finding a feasible solution for spacecraft or space robotic manipulator system. Moreover, the considered external disturbance input $\mathbf{w}(t)$ refers to a matched type, which is a conservative assumption for practical space multijoint robotic manipulator, forthe orbit disturbance is always unmatched. To this end, in this section, we will revisit the control design problem for the space multijoint robotic manipulator, where the model uncertainty $\Delta A(x)$ is treated as a matched nonlinearity of the system instead of a model uncertainty, and the considered disturbance input $\mathbf{w}(t)$ is an unmatched term. A novel backstepping control law with the finite-time integral sliding mode disturbance observer is developed, which can compensate the effects of model uncertainty $\Delta A(x)$ and infinite energy type disturbance input $\mathbf{w}(t)$.

We first recall the following dynamic equation for space multijoint robotic manipulator:

$$
\left[\begin{array}{l}
\dot{q} \\
\ddot{q}
\end{array}\right]=\left[\begin{array}{c}
\dot{q} \\
M_{\circ}^{-1} \Delta M(q) \ddot{q}-M_{\circ}^{-1}(q) \Delta c(q, \dot{q}) \dot{q}
\end{array}\right] .
$$

Then, we define the state vector as

$$
x=\left[\begin{array}{l}
q \\
\dot{q}
\end{array}\right]
$$

Thus, equation (26) can be rewritten as

$$
\dot{x}(t)=A x(t)+\triangle A(x)+B u(t)+\triangle H(\dot{x}, x),
$$

where

$$
\begin{aligned}
A & =\left[\begin{array}{ll}
0 & I \\
0 & 0
\end{array}\right], \\
B & =\left[\begin{array}{l}
0 \\
I
\end{array}\right], \\
\triangle A(x) & =\left[\begin{array}{ll}
0 & 0 \\
0 & M_{\circ}^{-1} \triangle M(q)
\end{array}\right] x(t) .
\end{aligned}
$$

As the previous discussion, in the practical space environment, there always exist unknown model nonlinearities and unmatched external disturbances, which are denoted as $f(x, t) \in R^{6}$ and $w(t) \in R^{6}$, respectively. Then, considering these effects in system (23), the system equation can be rewritten as

$$
\dot{x}(t)=A x(t)+\triangle A(x)+B u(t)+\triangle H(\dot{x}, x)+\phi(x, t),
$$

where

$$
\phi(x, t)=f(x, t)+w(t)
$$

In the following discussion, we will employ the finitetime integral sliding mode disturbance observer method to estimate the total nonlinearity $\phi(x, t)$, based on which a backstepping control law will be designed to stabilize system (24).

Before proceeding the subsequent design work, we decompose the system state vector $x(t)$ as $x(t)=\left[\begin{array}{ll}x_{1}^{T}(t) & x_{2}^{T}(t)\end{array}\right]^{T}$ with $x_{1}(t)=q(t)$ and $x_{2}(t)=\dot{q}(t)$ and decompose $\phi(x, t)$ as $\phi(x, t)=\left[\begin{array}{ll}\phi_{1}^{T}(x, t) & \phi_{2}^{T}(x, t)\end{array}\right]^{T}$. Then, system (26) can be decomposed as

$$
\begin{gathered}
{\left[\begin{array}{l}
\dot{x}_{1}(t) \\
\dot{x}_{2}(t)
\end{array}\right]=\left[\begin{array}{ll}
0 & I \\
0 & 0
\end{array}\right]\left[\begin{array}{l}
x_{1}(t) \\
x_{2}(t)
\end{array}\right]+\left[\begin{array}{cc}
0 & 0 \\
0 & M_{\circ}^{-1} \Delta M(q)
\end{array}\right]\left[\begin{array}{l}
x_{1}(t) \\
x_{2}(t)
\end{array}\right]} \\
+\left[\begin{array}{cc}
0 & 0 \\
0 & M_{\circ}^{-1} \Delta M(q)
\end{array}\right]\left[\begin{array}{l}
\dot{x}_{1}(t) \\
\dot{x}_{2}(t)
\end{array}\right]+\left[\begin{array}{l}
\phi_{1}(x, t) \\
\phi_{2}(x, t)
\end{array}\right]+\left[\begin{array}{l}
0 \\
I
\end{array}\right] u(t) .
\end{gathered}
$$

We now rewrite equation (32) as the following two subsystems:

$$
\begin{aligned}
& \dot{x}_{1}(t)=x_{2}(t)+\phi_{1}(x, t), \\
& \dot{x}_{2}(t)=-M_{\circ}^{-1} \triangle M(q) x_{2}(t)-M_{\circ}^{-1} \triangle M(q) \dot{x}_{2}(t)+\phi_{2}(x, t)+u(t) .
\end{aligned}
$$

Next, we define the following two backstepping variables as

$$
\left\{\begin{array}{l}
z_{1}(t)=x_{1}(t) \\
z_{2}(t)=x_{2}(t)-r(t)
\end{array}\right.
$$

where $r(t) \in R^{3 \times 1}$ is the virtual input vector to be designed, which is constructed as

$$
r(t)=-\left(k_{1} z_{1}(t)+\hat{\phi}(x, t)\right)
$$


where $k_{1} \in R^{3 * 3}$ is a positive definite diagonal matrix to be designed and $\phi(x, t) \in R^{3 * 1}$ is the estimation of the nonlinearity $\phi(x, t)$. With all the information in hand, we present the following finite-time integral sliding mode disturbance observer (FTISMDO) for system (32) as

$$
\left\{\begin{array}{l}
s_{0}=z_{1}(t)-p(t), \\
p \cdot=z_{2}(t)+r(t)+\hat{\phi}(x, t), \\
s_{1 j}(t)=\dot{s_{0 j}}(t)+\int_{0}^{t}\left[l_{1 j} \operatorname{sig}^{a_{1 j}}\left(s_{0 j}\right)+l_{2 j} \operatorname{sig}^{a_{2 j}}\left(\dot{s_{0 j}}\right)\right] \mathrm{d} t, \\
\dot{\hat{\phi}_{j}}(x, t)=l_{1 j} \operatorname{sig}^{a_{1 j}}\left(s_{0 j}\right)+l_{2 j} \operatorname{sig}^{a_{2 j}}\left(\dot{s_{0 j}}\right)+b_{1 j} \operatorname{sig}^{c_{1 j}}\left(s_{1 j}\right)+b_{2 j} s_{1}+L_{1 j} \operatorname{sgn}\left(s_{1 j}\right),
\end{array}\right.
$$

where $s_{0}=\left[\begin{array}{llll}s_{01} & s_{02} & s_{03} & s_{04}\end{array}\right]^{T}$, for $j=1,2,3,4 ; \quad L_{1 j} \geq$ $\sup _{t \geq 0}\left\|\dot{\phi}_{j}(x, t)\right\|$ denotes the norm bound of the unknown derivative of $\phi_{j}(x, t)$; and $l_{1 j}, l_{2 j}, a_{1 j}, a_{2 j}, b_{1 j}, b_{2 j}, L_{1 j}$ are the positive parameters to be designed. In particular, these parameters should satisfy $0<a_{1 j}<1, a_{2 j}=\left(a_{1 j} /\left(1+a_{1 j}\right)\right)$, $\operatorname{sig}^{a_{1 j}}\left(s_{0 j}\right)=\left|s_{0 j}\right|^{a_{1 j}} \operatorname{sgn}\left(s_{0 j}\right)$, and $\operatorname{sig}^{a_{2 j}}\left(\dot{s}_{0 j}\right)=\left|\dot{s}_{0 j}\right|^{a_{2 j}} \operatorname{sgn}\left(\dot{s}_{0 j}\right)$ where $\operatorname{sgn}\left(s_{0 j}\right)$ and $\operatorname{sgn}\left(\dot{s}_{0 j}\right)$ are two sign functions.

In observer (36), get

$$
\begin{aligned}
& \dot{s}_{0}=\dot{z}_{1}(t)-p(t) \cdot=x_{2}(t)+\phi_{1}(x, t)-\left(z_{2}(t)+r(t)+\hat{\phi}(x, t)\right)=\phi_{1}(x, t)-\hat{\phi}(x, t), \\
& \ddot{s}_{0}=\dot{\phi}_{1}(x, t)-\hat{\dot{\phi}}(x, t) .
\end{aligned}
$$

Combining equations (36)-(38) yields

$$
\begin{aligned}
\dot{s}_{1 j}(t) & =\ddot{s}_{0 j}(t)+l_{1 j} \operatorname{sig}^{a_{1 j}}\left(s_{0 j}\right)+l_{2 j} \operatorname{sig}^{a_{2 j}}\left(\dot{s}_{0 j}\right) \\
& =\widehat{\phi}_{1 j}(x, t)-b_{1 j} \operatorname{sig}^{c_{1 j}}\left(s_{1 j}\right)-b_{2 j} s_{1}-L_{1 j} \operatorname{sgn}\left(s_{1 j}\right) .
\end{aligned}
$$

$$
\begin{aligned}
\dot{V}_{1 j} & =s_{1 j} \dot{s}_{1 j}=s_{1 j}\left(\dot{\phi}_{1 j}(x, t)-b_{1 j} \operatorname{sig}^{c_{j}}\left(s_{1 j}\right)-b_{2 j} s_{1 j}-L_{1 j} \operatorname{sgn}\left(s_{1 j}\right)\right) \mathbb{Z} \\
& \leq-b_{1 j}|\operatorname{sig}|^{c_{j+1}}\left(s_{1 j}\right)-b_{2 j} s_{1 j}^{2} .
\end{aligned}
$$

So, $\dot{V}_{1 j}+b_{1 j}|s i g|^{c_{j+1}}\left(s_{1 j}\right)+b_{2 j} s_{1 j}^{2} \leq 0$.

$$
\dot{s_{0 j}}(t)+\int_{0}^{t}\left[l_{1 j} \operatorname{sig}^{a_{1 j}}\left(s_{0 j}\right)+l_{2 j} \operatorname{sig}^{a_{2 j}}\left(\dot{s_{0 j}}\right)\right] \mathrm{d} t=0 .
$$

Because of $(41), s_{0 j}(t), s_{0 j}(t), \ddot{s}_{0 j}(t)$ can converge in finite time.

So,

$$
\ddot{s}_{0 j}(t)=-l_{1 j} \operatorname{sig}^{a_{1 j}}\left(s_{0 j}\right)-l_{2 j} \operatorname{sig}^{a_{2 j}}\left(\dot{s}_{0 j}\right) .
$$

Based on equation $(41) s_{0 j}(t), s_{0 j}(t), \ddot{s}_{0 j}(t)$ can converge in finite time $T_{0 j}$ and so does $s_{0}$ in finite time $T_{s 0}=\max _{j}\left\{T_{0 j}\right\}$. It should be noted that Hurwitz condition should be met for $\ddot{s}_{0 j}(t)+l_{1 j} \operatorname{sig}^{a_{1 j}}\left(s_{0 j}\right)+l_{2 j} \operatorname{sig}^{a_{2 j}}\left(\dot{s}_{0 j}\right)=0$, and also $a_{2 j} \in(0,1), a_{1 j}=\left(a_{2 j} /\left(2-a_{2 j}\right)\right)$ or $a_{2 j} \in(0,1)$, $a_{1 j}=\left(a_{1 j} /\left(1+a_{1 j}\right)\right)$. Therefore, after finite time $T_{s_{0}}+$ $T_{s}, \dot{s}_{0}=0=\phi_{1}(x, t)-\phi(x, t)$, namely, the estimate error is able to converge in finite time $T_{s_{0}}+T_{s_{1}}$.
Design the Lyapunov function $V_{1 j}=(1 / 2) s_{1 j}^{2}$ : 


$$
\left\{\begin{array}{l}
y_{0}=f(t) \\
y_{r}=h_{r-1}=f^{(r-1)}(t), \quad r=1,2, \ldots, k .
\end{array}\right.
$$

In HOSMDs (37) and (43), $f(t)$ denotes $s_{0 i}(t)$, and $\dot{s}_{0 i}(t)$ can be calculated by $y_{1}(t)$.
Based on the FTISMDO (32) and HOSMDs (37)-(43), we now reconsider the backstepping variables $z_{1}(t)$ and $z_{2}(t)$. For $z_{1}(t)$, based on the virtual input vector $r(t)$ defined in equation (35), it is derived that

$$
\begin{aligned}
\dot{z_{1}} \cdot(t) & =\dot{x}_{1}(t)=x_{2}(t)+\phi(x, t) \\
& =z_{2}(t)+r(t)+\phi(x, t) \\
& =z_{2}(t)-\left(k_{1} z_{1}(t)+\hat{\phi}(x, t)\right)+\phi(x, t) \\
& =z_{2}(t)-k_{1} z_{1}(t)-\tilde{\phi}(x, t),
\end{aligned}
$$

where

On the other hand, for $z_{2}(t)$, it is derived that

$$
\widetilde{\phi}(x, t)=\hat{\phi}(x, t)-\phi(x, t)
$$

$$
\begin{aligned}
\dot{z}_{2}(t)= & \dot{x}_{2}(t)-\dot{r}(t) \\
= & -M_{\circ}^{-1} \triangle M(q) x_{2}(t)-M_{\circ}^{-1} \triangle M(q) \dot{x}_{2}(t)+\phi_{2}(x, t)+u(t)-\left(k_{1} \dot{z}_{1}(t)+\hat{\phi} \cdot(x, t)\right) \\
= & -M_{\circ}^{-1} \triangle M(q) x_{2}(t)-M_{\circ}^{-1} \triangle M(q) \dot{x}_{2}(t)+\phi_{2}(x, t)+u(t)-\left(k_{1} x_{2}(t)+k_{1} \phi(x, t)+\hat{\phi} \cdot(x, t)\right) \\
= & -M_{\circ}^{-1} \triangle M(q) z_{2}(t)+M_{\circ}^{-1} \triangle M(q) k_{1} z_{1}(t)+M_{\circ}^{-1} \triangle M(q) \hat{\phi}_{1}(x, t)-M_{\circ}^{-1} \triangle M(q) \dot{x}_{2}(t) \\
& +\phi_{2}(x, t)+u(t)-\left(k_{1}\left(z_{2}(t)+r(t)\right)+k_{1} \phi(x, t)\right) \\
= & u(t)-\hat{\phi} \cdot(x, t)+\phi_{2}(x, t)-k_{1}\left(z_{2}(t)+r(t)\right)+k_{1} \phi(x, t)+d(x, t),
\end{aligned}
$$

where the lumped disturbance vector $d(x, t)$ is defined as

$$
d(x, t)=M_{\circ}^{-1} \triangle M(q) k_{1} z_{1}(t)+M_{\circ}^{-1} \triangle M(q) \hat{\phi}_{1}(x, t)-M_{\circ}^{-1} \triangle M(q) \dot{x}_{2}(t) .
$$

As a result, we obtain the following system which is equivalent to equation (33):

$$
\left\{\begin{array}{l}
\dot{z}_{1}(t)=z_{2}(t)-k_{1} z_{1}(t)-\tilde{\phi}(x, t) \\
\dot{z}_{2}(t)=u(t)-\hat{\phi} \cdot(x, t)+\phi_{2}(x, t)-k_{1}\left(z_{2}(t)+r(t)\right)+k_{1} \phi(x, t)+d(x, t)
\end{array}\right.
$$

Theorem 1. Considering system (49), suppose that the model uncertainty $\triangle M(q)$ satisfies $\triangle M(q) \leq \beta_{1}$, where $\beta_{1}>0$ is a known constant; under the following adaptive control law: 


$$
\begin{aligned}
u(t)= & \hat{\phi} \cdot(x, t)-\left(I_{3}-k_{1}\right) \hat{\phi}_{1}(x, t)+k_{1}\left(z_{2}(t)+r(t)\right)-z_{1}(t) \\
& -\beta_{1}\left\|M_{\circ}^{-1}\right\|\left\|k_{1}\right\|\left\|z_{1}(t)\right\|+\beta_{1}\left\|M_{\circ}^{-1}\right\|\left\|\hat{\phi}_{1}(x, t)\right\|+\beta_{1}\left\|M_{\circ}^{-1}\right\|\left\|\dot{x}_{2}(t)\right\| \operatorname{sgn}\left(z_{2}(t)\right),
\end{aligned}
$$

the overall closed-loop system (49) is asymptotically stable.

$$
V_{1}(t)=\frac{1}{2} z_{1}^{T}(t) z_{1}(t)
$$

Proof. Considering system (49), we define the Lyapunov Calculating the time derivative yields function for the first subsystem of (49) as follows:

$$
\begin{aligned}
\dot{V}_{1}(t) & =\frac{1}{2} z_{1}^{T}(t)\left(z_{2}(t)-k_{1} z_{1}(t)-\widetilde{\phi}(x, t)\right) \\
& =-k_{1}\left\|z_{1}(t)\right\|+\frac{1}{2} z_{1}^{T}(t) z_{2}(t)-\frac{1}{2} z_{1}^{T}(t) \widetilde{\phi}(x, t) .
\end{aligned}
$$

Next, we design the Lyapunov function for the second subsystem of (49) as

$$
V_{2}(t)=\frac{1}{2} z_{2}^{T}(t) \dot{z}_{2}(t)+V_{1}(t)
$$

and then we have

$$
\begin{aligned}
\dot{V}_{2}(t)= & z_{2}^{T}(t) \dot{z}_{2}(t)+\dot{V}_{1}(t) \\
= & z_{2}^{T}(t)\left[u(t)-\hat{\phi} \cdot(x, t)+\phi_{2}(x, t)-k_{1}\left(z_{2}(t)+r(t)\right)+k_{1} \phi(x, t)+d(x, t)\right] \\
& -k_{1}\left\|z_{1}(t)\right\|+\frac{1}{2} z_{1}^{T}(t) z_{2}(t)-\frac{1}{2} z_{1}^{T}(t) \tilde{\phi}(x, t) .
\end{aligned}
$$

Considering the lumped disturbance $d(x, t)$ in equation (50), notice that the following inequality holds:

$$
\|d(x, t)\| \leq \beta_{1}\left\|M_{\circ}^{-1}\right\|\left\|k_{1}\right\|\left\|z_{1}(t)\right\|+\beta_{1}\left\|M_{\circ}^{-1}\right\|\left\|\hat{\phi}_{1}(x, t)\right\|+\beta_{1}\left\|M_{\circ}^{-1}\right\|\left\|\dot{x}_{2}(t)\right\| .
$$

If we substitute the control law (50) into equation (54), it is shown that 


$$
\begin{aligned}
\dot{V}_{2}(t) \leq & z_{2}^{T}(t)\left[u(t)-\hat{\phi} \cdot(x, t)+\phi_{2}(x, t)-k_{1}\left(z_{2}(t)+r(t)\right)+k_{1} \phi(x, t)\right] \\
& +\beta_{1}\left\|M_{\circ}^{-1}\right\|\left\|k_{1}\right\|\left\|z_{1}(t)\right\|+\beta_{1}\left\|M_{\circ}^{-1}\right\|\left\|\hat{\phi}_{1}(x, t)\right\|+\beta_{1}\left\|M_{\circ}^{-1}\right\|\left\|\dot{x}_{2}(t)\right\| \\
& -k_{1}\left\|z_{1}(t)\right\|+\frac{1}{2} z_{1}^{T}(t) z_{2}(t)-\frac{1}{2} z_{1}^{T}(t) \tilde{\phi}(x, t), \\
\leq & z_{2}^{T}(t) \hat{\phi} \cdot(x, t)-\left(I_{3}-k_{1}\right) \hat{\phi}_{1}(x, t)+k_{1}\left(z_{2}(t)+r(t)\right)-z_{1}(t)-\beta_{1}\left\|M_{\circ}^{-1}\right\|\left\|k_{1}\right\|\left\|z_{1}(t)\right\| \\
& +\beta_{1}\left\|M_{\circ}^{-1}\right\|\left\|\hat{\phi}_{1}(x, t)\right\|+\beta_{1}\left\|M_{\circ}^{-1}\right\|\left\|\dot{x}_{2}(t)\right\| \operatorname{sgn}\left(z_{2}(t)\right) \\
& +z_{2}^{T}(t)\left[-\hat{\phi} \cdot(x, t)+\phi_{2}(x, t)-k_{1}\left(z_{2}(t)+r(t)\right)+k_{1} \phi(x, t)\right] \\
& +\beta_{1}\left\|M_{\circ}^{-1}\right\|\left\|k_{1}\right\|\left\|z_{1}(t)\right\|+\beta_{1}\left\|M_{\circ}^{-1}\right\|\left\|\hat{\phi}_{1}(x, t)\right\|+\beta_{1}\left\|M_{\circ}^{-1}\right\|\left\|\dot{x}_{2}(t)\right\| \\
& -k_{1}\left\|z_{1}(t)\right\|+\frac{1}{2} z_{1}^{T}(t) z_{2}(t)-\frac{1}{2} z_{1}^{T}(t) \tilde{\phi}(x, t) .
\end{aligned}
$$

By some calculation, we have that

$$
\dot{V}_{2}(t) \leq-\tilde{\phi}(x, t)-k_{1}\left\|z_{1}(t)\right\|-z_{1}^{T}(t) \tilde{\phi}(x, t) \leq-k_{1}\left\|z_{1}(t)\right\|<0
$$

holds for $\forall z(t) \in R^{6}, z(t) \neq 0$, which means that the overall closed-loop system (49) is asymptotically stable. Thus, we complete the proof.

\section{Simulation Experiment and Result Analysis}

3.1. Robust Optimal Controller Simulation Results. The redundant manipulator has seven degrees of freedom, and the floating base has six degrees of freedom. The structure of the space robot is established by the DH method, as shown in Figure 1, the dynamic parameters are shown in Table 1, and the total detumbling chaser is illustrated in Figure 2.

Because optimal control, for a system of $\dot{x}=A+B u$ to design a suitable state feedback control rate $u=-K x(t)$, make the performance index

$$
J=\int_{0}^{\infty}\left(x^{T}(t) Q(t) x(t)+u^{T}(t) R(t) u(t)\right) \mathrm{d} t,
$$

where $Q(t)$ is $n \times n$ of real symmetric semipositive definite weighted matrices and $R(t)$ is $m \times m$ of a real symmetric positive definite matrix.

$$
\begin{aligned}
& Q_{1}=\text { eye }(13), \\
& R_{1}=30 \text { eye }(13),
\end{aligned}
$$$$
\text { gamma }=1.9 \text {. }
$$

From equation (25), we obtain the corresponding parameters as

$$
\begin{aligned}
B & =[\operatorname{eye}(13) \operatorname{zeros}(13)] \\
A_{1} & =\operatorname{sqrt}\left(\operatorname{inv}\left(\operatorname{inv}(R)-\left(\frac{1}{\operatorname{gama} \hat{2}}\right) \operatorname{eye}(13)\right)\right) \\
T_{11} & =A_{1}^{\prime} Q_{1} \\
T_{12} & =A_{1}^{\prime} * R_{1} \\
T_{0} & =\left[T_{11} T_{12} ; \operatorname{zeros}(13) \operatorname{eye}(13)\right] \\
u & =-\operatorname{pinv}(R) B T_{0} D e
\end{aligned}
$$

In this simulation, the end of the manipulator moves from point $A\left(r_{A}=\left[\begin{array}{llllll}5.83 & 0 & 0 & 0 & 0 & 0\end{array}\right]^{T}\right)$ to point $B\left(r_{B}=\left[\begin{array}{llllll}5 & -2 & 1 & 0 & 0 & 0\end{array}\right]^{T}\right)$. At the moment of $t=1 \mathrm{~s}$, the interference force of $200 \mathrm{~N}$ is applied to the terminal flexible reducer brush, with the action time being $0.01 \mathrm{~s}$, which can be regarded as an impulse force during the racemization process.

The initial pose and final pose of the space racemization robot are known, and the trajectory planning is carried out within a specified time. After planning, the position changes of the end points are shown in Figure 3. The desired trajectory of end-line velocity can be obtained by differentiation, as shown in Figure 4. Among them, the terminal attitude does not change, so it is unnecessary to repeat the terminal attitude planning. 


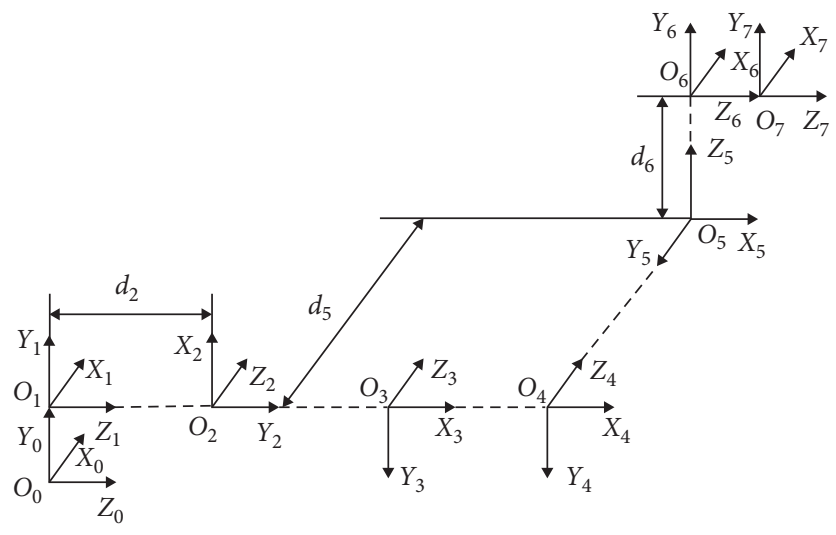

Figure 1: Structure of space robot.

TABLE 1: Kinetic parameters.

\begin{tabular}{|c|c|c|c|c|c|c|c|c|}
\hline Parameter name & Matrix & Joint1 & Joint2 & Joint3 & Joint4 & Joint5 & Joint6 & Joint7 \\
\hline Length $a(\mathrm{~m})$ & - & 0 & 0 & 1 & 1 & 0 & 0 & 0 \\
\hline Angle $\alpha\left(^{\circ}\right)$ & - & 90 & 90 & 0 & 0 & 90 & 90 & 0 \\
\hline Joint distance $d(\mathrm{~m})$ & - & 0 & 0.1 & 0 & 0 & 0.3 & 0.1 & 0 \\
\hline Joint angle $\theta\left(^{\circ}\right)$ & 一 & $\theta 1$ & $\theta 2$ & $\theta 3$ & $\theta 4$ & $\theta 5$ & $\theta 6$ & $\theta 7$ \\
\hline Parameter name & Matrix & Link1 & Link2 & Link3 & Link4 & Link5 & Link6 & Link7 \\
\hline$m(\mathrm{~kg})$ & 2811 & 2.8 & 2.8 & 25.39 & 25.39 & 2.8 & 2.8 & 10.6 \\
\hline$I x\left(\mathrm{~kg} \cdot \mathrm{m}^{2}\right)$ & 473 & 0.005 & 0.005 & 2.76 & 2.76 & 0.005 & 0.005 & 1.33 \\
\hline$I y\left(\mathrm{~kg} \cdot \mathrm{m}^{2}\right)$ & 473 & 0.005 & 0.005 & 2.76 & 2.76 & 0.005 & 0.005 & 1 \\
\hline$I z\left(\mathrm{~kg} \cdot \mathrm{m}^{2}\right)$ & 467 & 0.005 & 0.005 & 0.03 & 0.03 & 0.005 & 0.005 & 1.5 \\
\hline
\end{tabular}

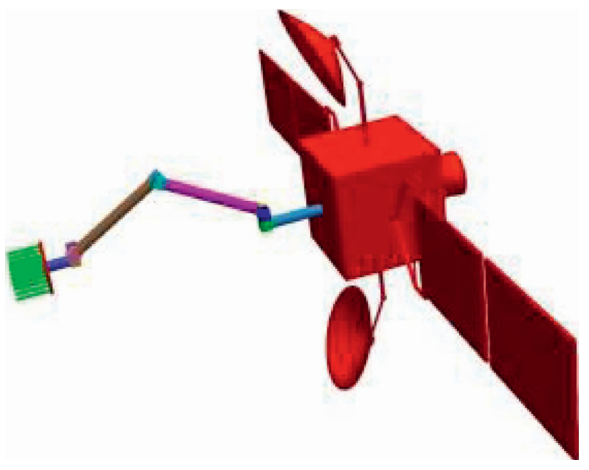

FIgUre 2: Space debris detumbling chaser.

The end planning trajectory in the above Cartesian space is transformed into the joint space. The joint angle, joint angular velocity, and joint angular acceleration after planning are shown in Figures 5-7, respectively. The first $10 \mathrm{~s}$ is the planned motion mode, and the last $5 \mathrm{~s}$ is the reserved stabilization time of the manipulator.

For the planned trajectory of the space robot, the $\mathbf{H}_{\infty}$ robust optimal controller proposed in this paper is adopted, and the switching frequency of joint control torque is high. In order to simulate the actual working effect, a low-pass filter is incorporated. The joint torque is shown in Figure 8, while the joint angle error is shown in Figure 9. The upper and lower bounds of the control torque are small, and with the gradual convergence of the tracking error, the system is

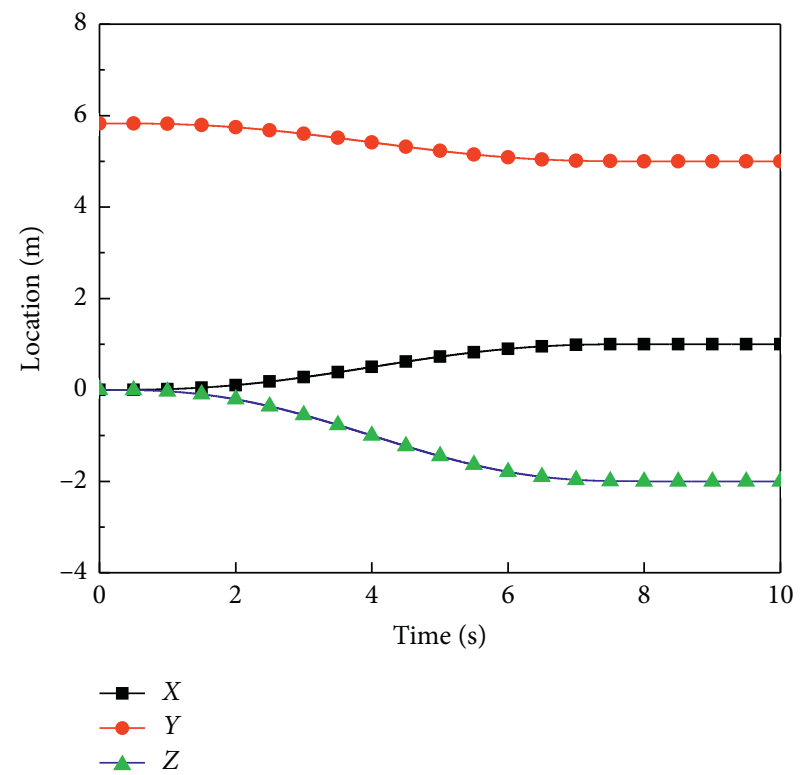

Figure 3: Terminal location planning (m).

asymptotically stable, and the control torque gradually decreases and ultimately converges.

$\mathbf{H}_{\infty}$ robust optimal controller designed in this paper can deal with disturbances with stronger robustness. As for the joint angle error, $\mathbf{H}_{\infty}$ robust optimal controller can maintain stability and suppress the tremor within only $0.5 \mathrm{~s}$. If 


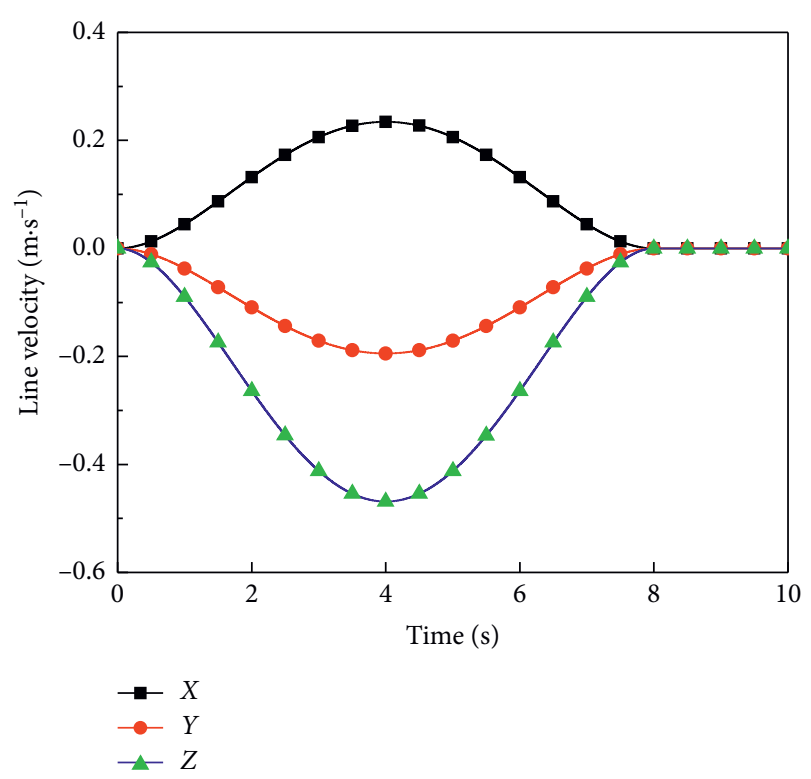

FIgURE 4: Terminal line velocity planning $(\mathrm{m} / \mathrm{s})$.

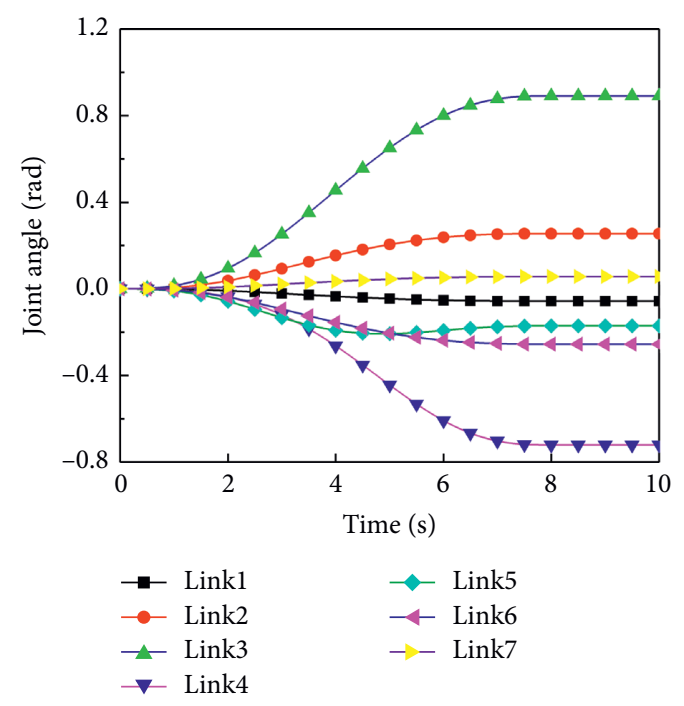

Figure 5: Planning joint angles (rad).

disturbance occurs, the $\mathbf{H}_{\infty}$ robust optimal controller can generate larger control torques to suppress vibration, which is conducive to the racemization process. Moreover, the $\mathbf{H}_{\infty}$ robust optimal controller has smaller tracking error and higher tracking accuracy and can stabilize the system within planned time, and thus its advantage of accuracy and effectiveness is clearly verified.

3.2. Backstepping Control Simulation Results. In this section, a simulation of the stabilization problem of a space multijoint robotic manipulator is implemented to illustrate the effectiveness of the proposed backstepping control law. Considering the double-joint robotic

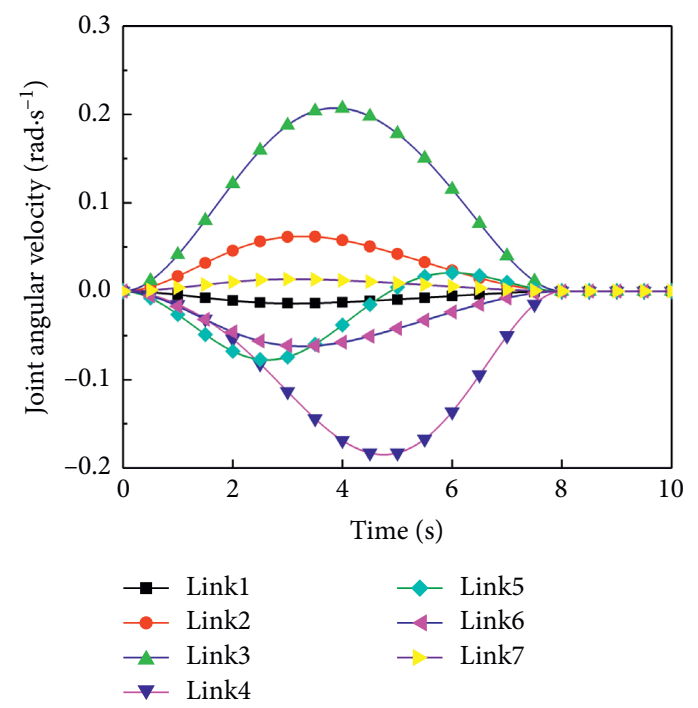

Figure 6: Planning joint angular velocity ( $\mathrm{rad} / \mathrm{s})$.

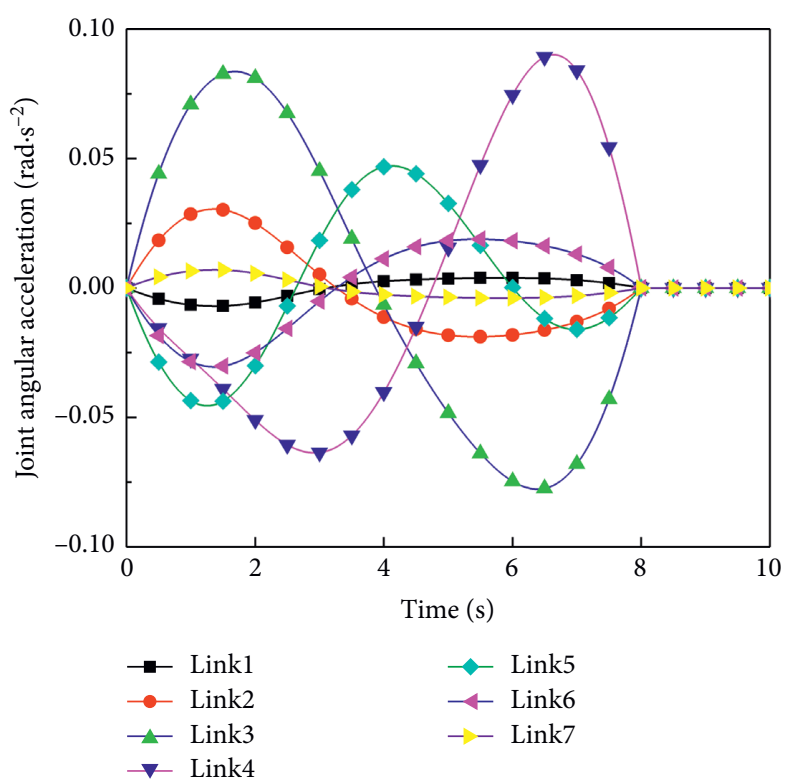

Figure 7: Plan for joint angular acceleration $\left(\mathrm{rad} / \mathrm{s}^{-2}\right)$.

manipulator, the mechanical model of the manipulator is shown in Figure 10. For manipulator model (1) with angular state variables $q=\left[\begin{array}{ll}q_{1} & q_{2}\end{array}\right]^{T}$ and angular velocity variables $\dot{q}=\left[\begin{array}{ll}\dot{q}_{1} & \dot{q}_{2}\end{array}\right]^{T}$, the initial attitude orientation and attitude angular velocity of the manipulator are set as

$$
\begin{aligned}
& q(0)=\left[\begin{array}{ll}
\frac{\pi}{3} & -\frac{\pi}{6}
\end{array}\right]^{T} \mathrm{rad}, \\
& \dot{q}(0)=\left[\begin{array}{ll}
0 & 0
\end{array}\right]^{T} \mathrm{rad} / \mathrm{s} .
\end{aligned}
$$

In addition, the inertia matrix, Coriolis force, and centrifugal force matrix are set as follows: 


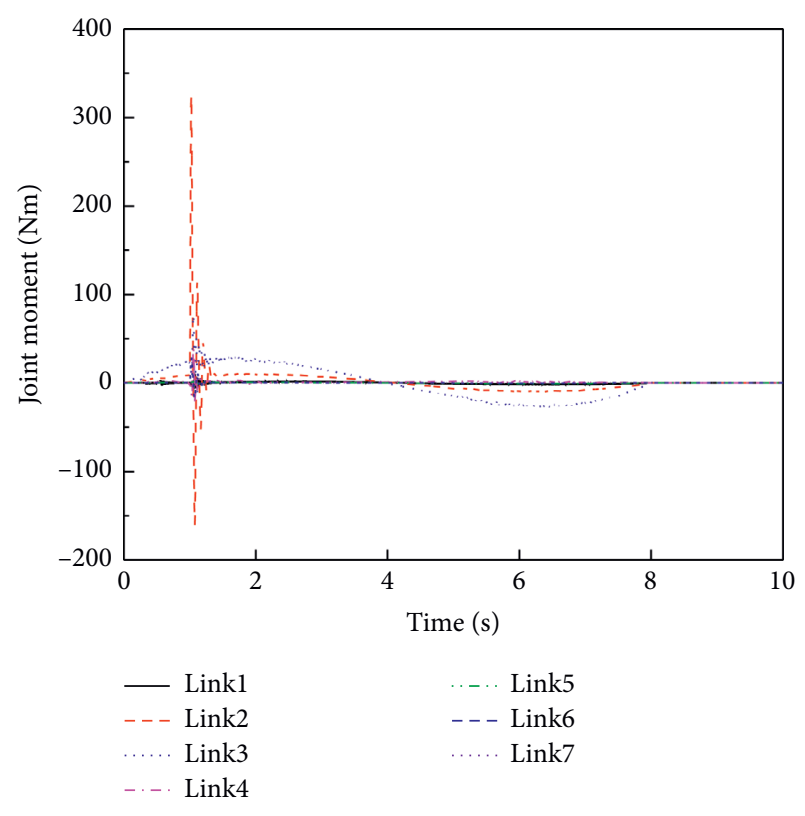

FIGURE 8: Joint control torque (Nm).

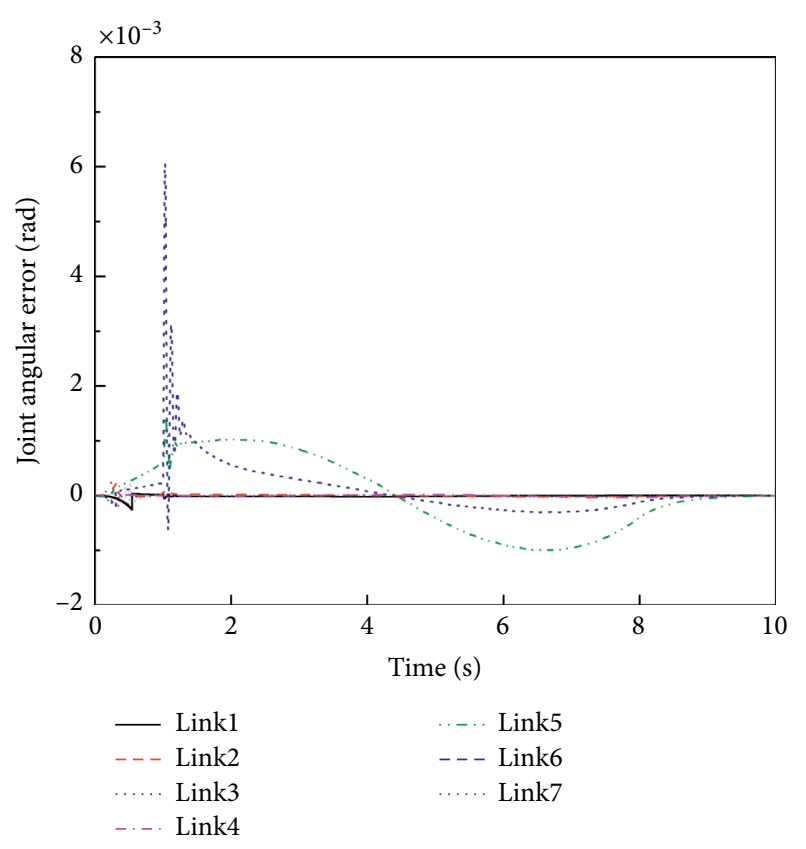

FIGURE 9: Joint angle tracking error (rad).

$$
\begin{aligned}
M_{0}(q) & =\left[\begin{array}{ll}
M_{1} & M_{2} \\
M_{2} & M_{3}
\end{array}\right], \\
C_{0}(q, \dot{q}) & =\left[\begin{array}{cc}
0 & C_{1} \\
C_{2} & 0
\end{array}\right],
\end{aligned}
$$

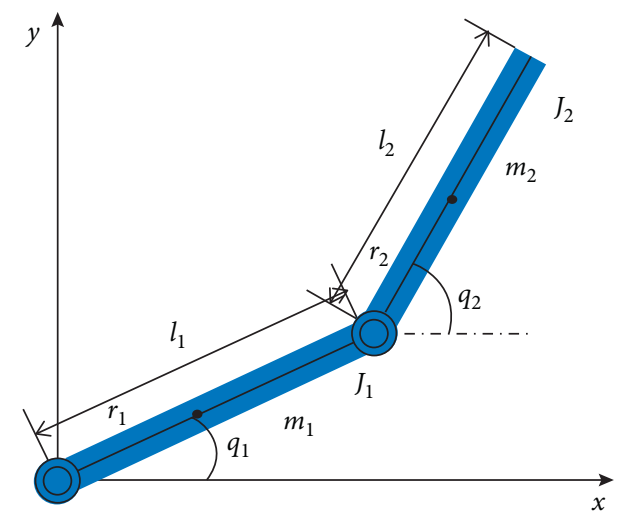

Figure 10: Mechanical model of the double-joint robotic manipulator.

$$
\begin{aligned}
& M_{1}=J_{1}+m_{1} r_{1}^{2}+m_{2} l_{1}^{2}, \\
& M_{2}=m_{1} r_{1} l_{1} \cos \left(q_{2}-q_{1}\right), \\
& M_{3}=J_{2}+m_{2} r_{2}^{2}, \\
& C_{1}=-m_{2} r_{2} l_{1} \dot{q}_{2} \sin \left(q_{2}-q_{1}\right), \\
& C_{2}=-m_{2} r_{2} l_{1} \dot{q}_{1} \sin \left(q_{2}-q_{1}\right),
\end{aligned}
$$

and the parameters above are selected as

$$
\begin{aligned}
J_{1} & =0.1169 \mathrm{~kg} \cdot \mathrm{m}^{2}, \\
J_{2} & =0.0042 \mathrm{~kg} \cdot \mathrm{m}^{2}, \\
m_{1} & =6.1643 \mathrm{~kg}, \\
m_{2} & =1.3212 \mathrm{~kg}, \\
l_{1} & =0.27 \mathrm{~m}, \\
l_{2} & =0.23 \mathrm{~m}, \\
r_{1} & =0.1235 \mathrm{~m}, \\
r_{2} & =0.1133 \mathrm{~m} .
\end{aligned}
$$

The uncertainties of the system are described as

$$
\begin{aligned}
\Delta M & =\left[\begin{array}{cc}
\Delta M_{1} & \Delta M_{2} \\
\Delta M_{2} & \Delta M_{3}
\end{array}\right], \\
\Delta C & =\left[\begin{array}{cc}
0 & \Delta C_{1} \\
\Delta C_{2} & 0
\end{array}\right],
\end{aligned}
$$

with

$$
\begin{aligned}
\Delta M_{1} & =0.01+0.004 \varepsilon+0.014 \varepsilon^{2}, \\
\Delta M_{2} & =0.018 \varepsilon \cos \left(q_{2}-q_{1}\right), \\
\Delta M_{3} & =0.008+0.007 \varepsilon+0.015 \varepsilon^{2}, \\
C_{1} & =-0.015 \varepsilon \dot{q}_{2} \sin \left(q_{2}-q_{1}\right), \\
C 2 & =-0.015 \varepsilon \dot{q}_{1} \sin \left(q_{2}-q_{1}\right),
\end{aligned}
$$

where 
where $\varepsilon \in[0,1]$ describes the size of the uncertainty and it is designed as $\varepsilon=0.5$. The measurement errors of state variables are given as

$$
\begin{aligned}
& \Delta x_{1}=10^{-5}\left[\begin{array}{c}
10 \sin (5+0.5 t) \\
8 \sin (3+0.7 t)
\end{array}\right], \\
& \Delta x_{2}=10^{-5}\left[\begin{array}{l}
3 \sin (5+0.5 t) \\
2 \sin (3+0.7 t)
\end{array}\right] .
\end{aligned}
$$

The attitude angular and angular velocity trajectories are depicted in Figures 11 and 12 , respectively, in which ideal performances are achieved.

The sign (.) function in control law (41) may lead to undesirable chattering when the sliding manifold crosses the sliding mode surface $S(t)=0$. To avoid this phenomenon, the sign $(\cdot)$ function can be replaced by

$$
\nu(t)=\frac{S(t)}{\operatorname{norm}(S(t))+\varepsilon_{1}},
$$

where $\varepsilon_{1}>0$ refers to the size of the bounder layer, which offers a continuous approximation to the sliding mode controller inside the boundary layer. The time response of the controller is presented in Figure 13, of which the upper bound is limited to $2 \mathrm{Nm}$.

For the designed finite-time integral sliding mode disturbance observer, the initial estimated value is set as $\widehat{\phi}_{1}(0)=\left[\begin{array}{ll}0 & 0\end{array}\right]^{T}$, and the gain parameters in observer (36) are set as follows:

$$
\begin{aligned}
& l_{1}=0.01\left[\begin{array}{ll}
8 & 0 \\
0 & 8
\end{array}\right], \\
& l_{2}=0.01\left[\begin{array}{ll}
7 & 0 \\
0 & 7
\end{array}\right], \\
& a_{1}=0.01\left[\begin{array}{ll}
4 & 0 \\
0 & 4
\end{array}\right], \\
& a_{2}=0.01\left[\begin{array}{ll}
4 & 0 \\
0 & 4
\end{array}\right] ; \\
& c_{1}=0.01\left[\begin{array}{ll}
4 & 0 \\
0 & 4
\end{array}\right], \\
& b_{1}=0.01\left[\begin{array}{ll}
7 & 0 \\
0 & 7
\end{array}\right], \\
& b_{2}=0.01\left[\begin{array}{ll}
8 & 0 \\
0 & 8
\end{array}\right], \\
& L_{1}=0.01\left[\begin{array}{ll}
8 & 0 \\
0 & 8
\end{array}\right],
\end{aligned}
$$

The estimation performance is given in Figure 14, in which ideal estimation is achieved in finite time. Thus, the

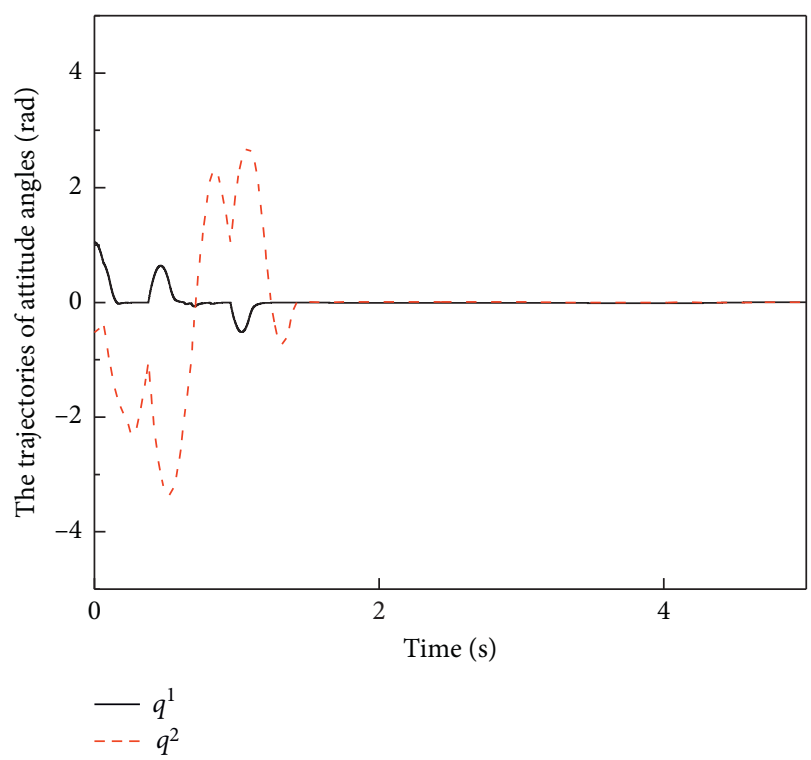

FIgURE 11: The trajectories of attitude angles (rad).

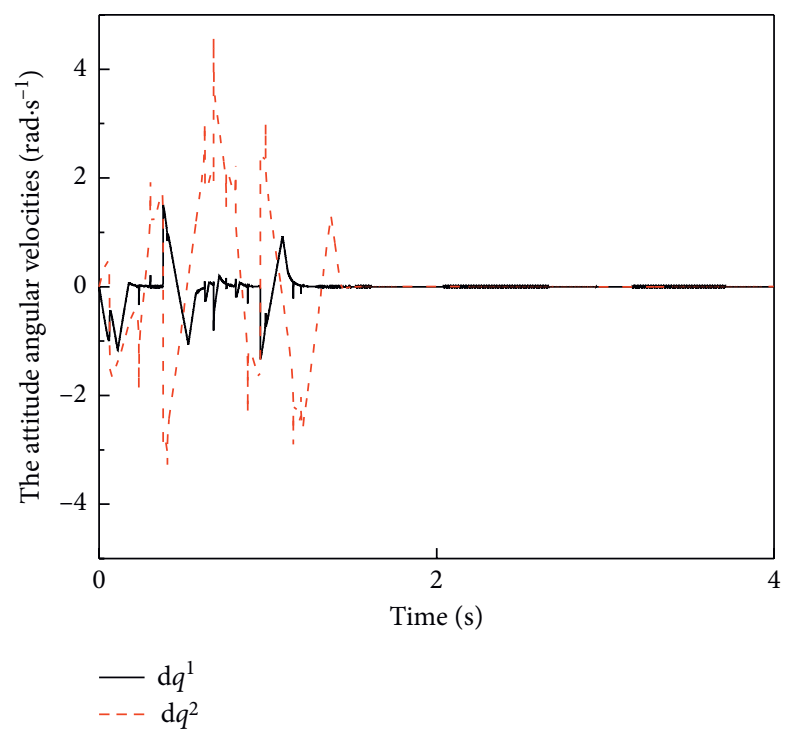

Figure 12: The trajectories of attitude angular velocities ( $\mathrm{rad} / \mathrm{s})$.

improved control performance of the backstepping controller with finite-time observer is demonstrated fully.

$$
k_{1}=\left[\begin{array}{cc}
0.5 & 0 \\
0 & 0.5
\end{array}\right] \text {. }
$$

The uncertainties of the system are described as follows: at $0 \mathrm{~s}, 10 \mathrm{~s}$, and $30 \mathrm{~s}$, moments of $15 \mathrm{Nm}$ lasting for $0.02 \mathrm{~s}$ are entered in each dimension as a pulse. For the first dimension, a moment of $15 \mathrm{Nm}$ acting for $0.03 \mathrm{~s}$, with an action period of $10 \mathrm{~s}$, is entered as a pulse. For the second dimension, a moment of $10 \mathrm{Nm}$ acting for $0.02 \mathrm{~s}$, with a period of $10 \mathrm{~s}$ is entered as a pulse. A set of random numbers 


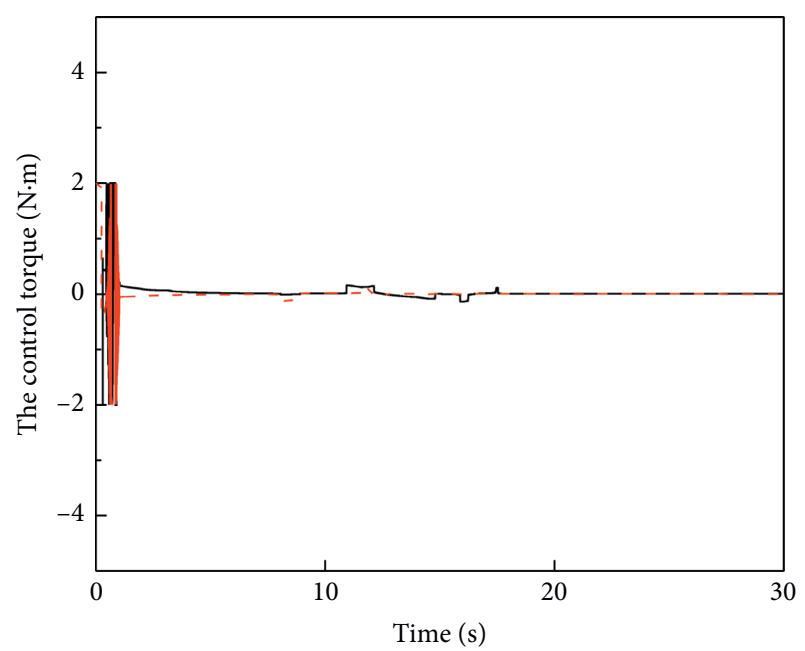

\section{— Link1}

- - - Link2

Figure 13: The control torque (Nm).

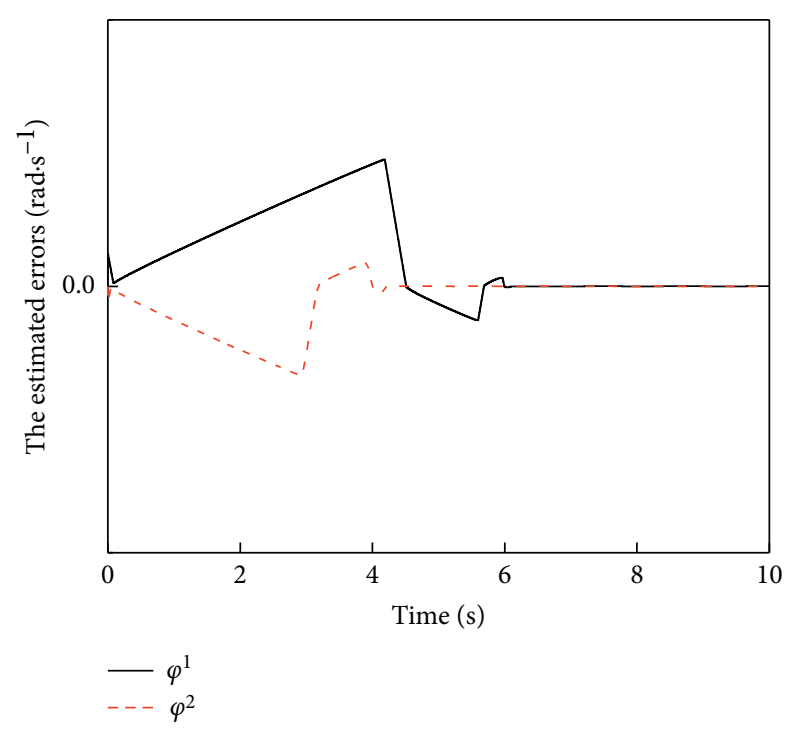

FIgURE 14: The estimated errors of FTISMDO ( $\mathrm{rad} / \mathrm{s})$.

between $\left[-4 * 10^{(-6)}, 4 * 10^{(-6)}\right]$ is generated as a random disturbance.

The attitude and angular velocity trajectories are depicted in Figures 15 and 16, respectively, in which ideal performances are achieved under the condition that a pulse acts on the target at $0 \mathrm{~s}, 10 \mathrm{~s}$, and $30 \mathrm{~s}$.

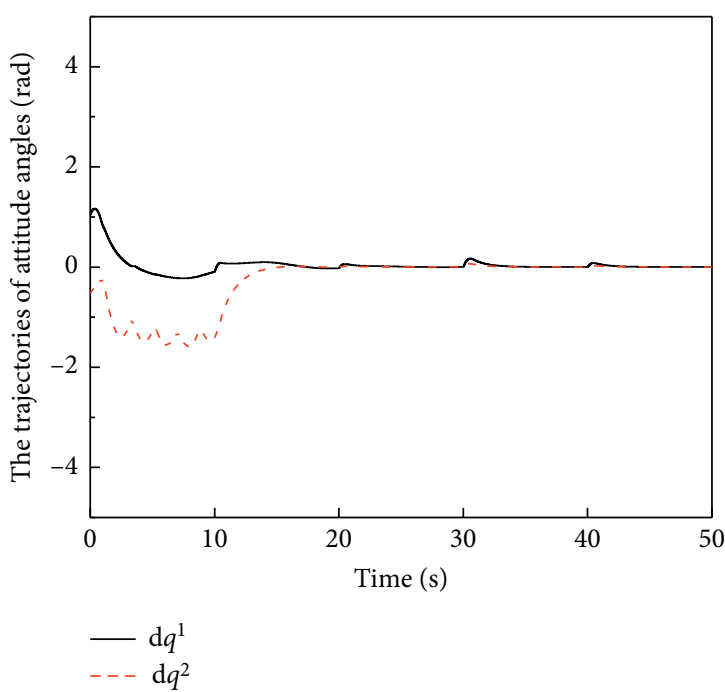

FIgURE 15: The trajectories of attitude angles (rad).

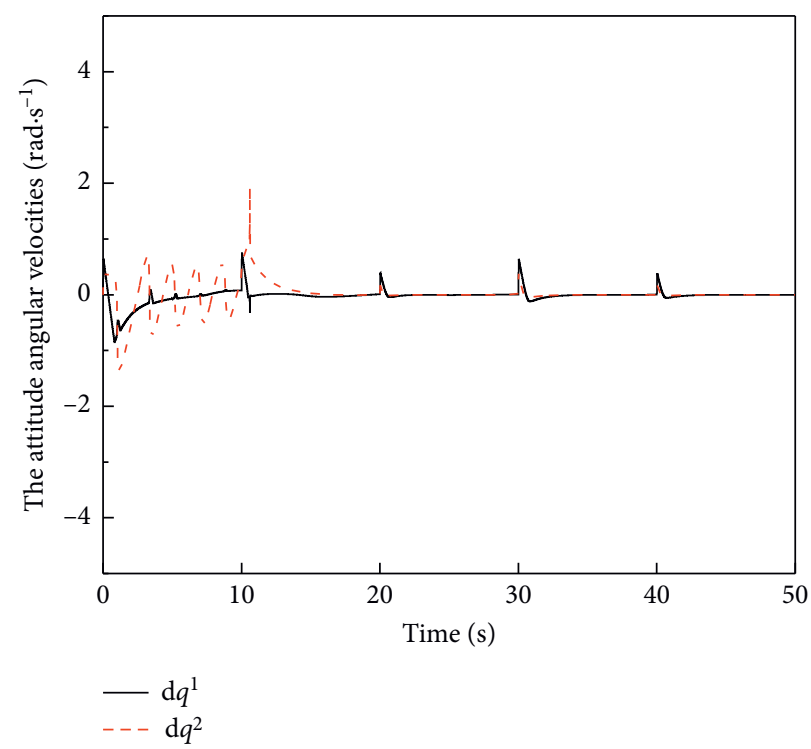

FIgURE 16: The trajectories of attitude angular velocities ( $\mathrm{rad} / \mathrm{s})$.

The time response of the controller is presented in Figure 17, of which the upper bound is limited to $2 \mathrm{Nm}$.

The estimated performance is given in Figure 18, where the ideal estimate is achieved in finite time. Thus, given multiple external disturbances, periodic disturbances, and random disturbances, the improved control performance of 


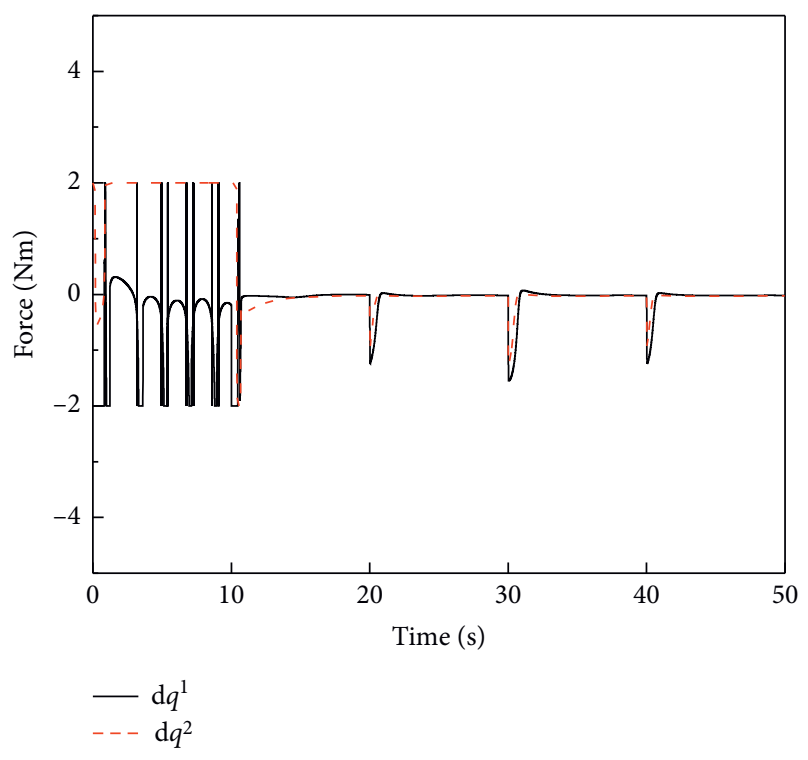

Figure 17: The control torque (Nm).

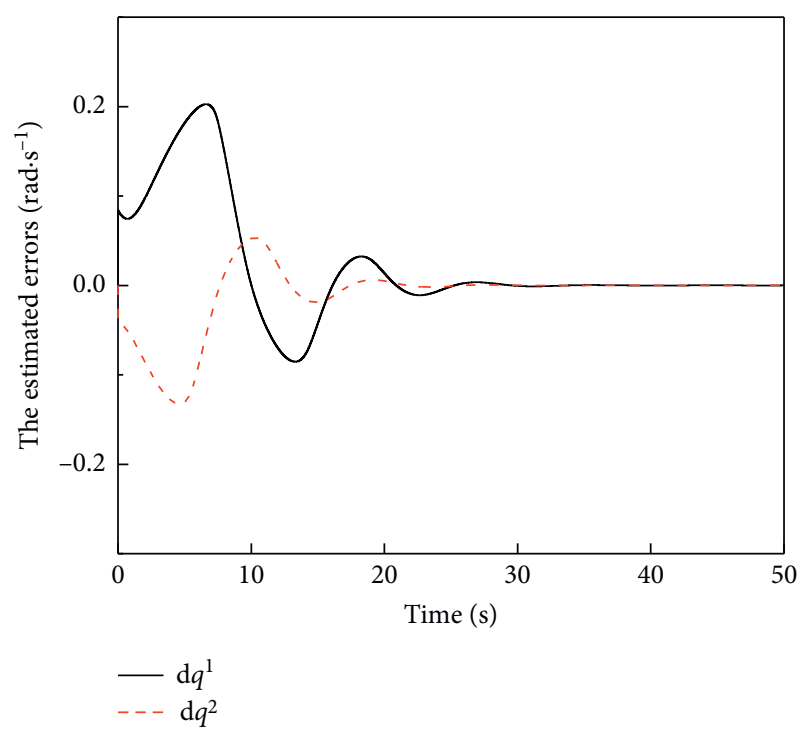

Figure 18: The estimated errors of FTISMDO ( $\mathrm{rad} / \mathrm{s})$.

an inverse stepper controller with a finite-time observer can fulfil the requirements.

\section{Conclusion}

In this paper, the dynamic model of a space debris detumbling system is established. For the manipulator with uncertainty and external disturbance, we first design a $\mathrm{H}_{\infty}$ robust optimal controller based on a linear quadratic performance index. The essence of $\mathrm{H}_{\infty}$ control is to minimize the $\mathrm{H}_{\infty}$ norm of the error transfer function when the interference is bounded and the maximum interference is considered. At the same time, the optimal control makes the system have robust optimal performance under a specified performance index. It can be proved that the robust state feedback controller can effectively compensate the uncertainties and bounded external disturbances, which means the manipulator can accurately track the desired trajectory, and the quadratic performance index reaches the optimal. Then, assuming that the disturbance is unmatched, a backstepping controller with a finite-time integral sliding mode disturbance observer is designed to further reduce the conservativeness existing in first robust controller and improve the control accuracy. The stability analysis shows that the finite-time integral sliding mode disturbance observer can efficiently compensate the unmatched lumped uncertainty in finite time..As this paper is a finite-time backstepping control of an observer, further research on finitetime backstepping control of an controlleron redundant robotic arms will be done in the future.

\section{Data Availability}

The data used to support the findings of this study are included within the article.

\section{Conflicts of Interest}

The authors declare that they have no conflicts of interest.

\section{References}

[1] Y. Lu, X. Liu, Y. Zhou et al., "Review of detumbling technologies for active removal of uncooperative targets," Acta Aeronautica et Astronautica Sinica, vol. 39, no. 1, pp. 38-50, 2018, (in Chinese).

[2] X. Zhou, The Simulation Analysis of Active Debris Removal of Multiple Targets in a Single task, The University of Chinese Academy of Sciences, Beijing, China, 2017pp. 3-8, (in Chinese).

[3] S. Kawamoto, K. Matsumoto, and S. Wakabayashi, "Ground experiment of mechanical impulse method for uncontrollable satellite capturing," in Proceeding Of the 6th International Symposium On Artificial Intelligence And Robotics \& Automation In Space (I-SARAS), Montreal, Canada, June 2001.

[4] T. Sinn, T. Thakore, and P. Maier, "Space debris removal using self-inflating adaptive membrane," in Proceedings of the 63rd International Astronautical Congress, Bremen, Germany, September 2012.

[5] K. Daneshjou and R. Alibakhshi, "Multibody dynamical modeling for spacecraft docking process with spring-damper buffering device: a new validation approach," Advances in Space Research, vol. 61, no. 1, pp. 497-512, 2018.

[6] S.-I. Nishida and S. Kawamoto, "Strategy for capturing of a tumbling space debris," Acta Astronaut, vol. 68, no. 1, pp. 113-120, 2011.

[7] P. Huang, M. Wang, Z. Meng, F. Zhang, Z. Liu, and H. Chang, "Reconfigurable spacecraft attitude takeover control in postcapture of target by space manipulators," Journal of the Franklin Institute, vol. 353, no. 9, pp. 1985-2008, 2016.

[8] P. Huang, F. Zhang, Z. Meng, and Z. Liu, "Adaptive control for space debris removal with uncertain kinematics, dynamics and states," Acta Astronautica, vol. 128, pp. 416-430, 2016.

[9] Y. Geng, W. Lu, and X. Chen, "Attitude synchronization control of on-orbit servicing spacecraft with respect to out-ofcontrol target," Journal of Harbin Institute of Technology, vol. 44, no. 1, pp. 1-6, 2012, (in Chinese). 
[10] P. Huang, Y. Xu, and B. Liang, "Contact and impact dynamics of space manipulator and free-flying target," in Proceedings of the 2005 IEEE/RSJ International Conference On Intelligent Robots And Systems, pp. 1181-1186, Edmonton, Canada, August 2005.

[11] P. Cheng, S. He, X. Luan, and F. Liu, "Finite-region asynchronous Ho control for 2D Markov jump systems," Automatica, vol. 129, no. 18, Article ID 109590, 2021.

[12] P. Cheng, S. He, J. Cheng, X. Luan, and F. Liu, "Finite-time $\mathrm{L}_{2^{-}}$ gain asynchronous control for continuous-time positive hidden markov jump systems via T-S fuzzy model approach," IEEE Transactions on Cybernetics, vol. 51, pp. 1-8, 2020.

[13] P. Cheng, S. He, J. Cheng, X. Luan, and F. Liu, "Asynchronous output feedback control for a class of conic-type nonlinear hidden Markov jump systems within a finite-time interval," IEEE Transactions on Systems, Man, and Cybernetics: Systems, pp. 1-8, 2020.

[14] W. Zhou, Y. Wang, C. K. Ahn, J. Cheng, and C. Chen, "Adaptive fuzzy backstepping-based formation control of unmanned surface vehicles with unknown model nonlinearity and actuator saturation," IEEE Transactions on Vehicular Technology, vol. 69, no. 12, pp. 14749-14764, 2020.

[15] W. Yan, P. Zhou, Y. Liang, Y. Wang, and D. Duan, “Adaptive finite-time neural backstepping control for multi-input and multi-output state-constrained nonlinear systems using tangent-type nonlinear mapping," International Journal of Roust And Nonlinear Control, vol. 30, pp. 5559-5578, 2020.

[16] Y. Wei, Y. Wang, C. K. Ahn, and D. Duan, "IBLF-based finitetime adaptive fuzzy output-feedback control for uncertain MIMO nonlinear state-constrained systems," IEEE Transactions On Fuzzy Systems, 2020.

[17] Y. Wang, Y. Gao, H. R. Karimi et al., "Sliding mode control of fuzzy singularly perturbed systems with application to electric circuit," IEEE Transactions on Systems Man \& Cybernetics Systems, vol. 48, pp. 1-9, 2017.

[18] Y. Wang, Y. Xia, H. Li, and P. Zhou, "A new integral sliding mode design method for nonlinear stochastic systems," Automatica, vol. 90, pp. 304-309, 2018.

[19] Z. Liu, H. R. Karimi, and J. Yu, "Passivity-based robust sliding mode synthesis for uncertain delayed stochastic systems via state observer," Automatica, vol. 111, no. 111, 2020.

[20] J. Zhai and H. R. Karimi, "Universal adaptive control for uncertain nonlinear systems via output feedback," Information Sciences, vol. 500, pp. 140-155, 2019.

[21] H. Yang and M. Tan, "Sliding mode control for flexible-link manipulators based on adaptive neural networks," International Journal of Automation and Computing, vol. 15, no. 2, pp. 239-248, 2018.

[22] H. Yang and J. Liu, "An adaptive RBF neural network control method for a class of nonlinear systems," IEEE/CAA Journal of Automatica Sinica, vol. 5, no. 2, pp. 457-462, 2018.

[23] H. Sun, L. Hou, G. Zong, and L. Guo, "Composite antidisturbance attitude and vibration control for flexible spacecraft," IET Control Theory \& Applications, vol. 11, no. 14, pp. 2383-2390, 2017. 